\title{
Family models of independence/interdependence and their intergenerational similarity in Germany, Turkey, and India
}

\author{
Boris Mayer ${ }^{2 *}$, Gisela Trommsdorff ${ }^{a}$, Cigdem Kagitcibasi ${ }^{b}$ and Ramesh C. Mishra ${ }^{c}$ \\ ${ }^{a}$ Department of Psychology, University of Konstanz, P.O. Box 31, 78457 Konstanz, Germany; ${ }^{b}$ Department of Psychology, Koc \\ University, Rumelifeneri Yolu, 34450 Sariyer Istanbul, Turkey; ${ }^{\circ}$ Department of Psychology, Banaras Hindu University, Varanasi 221005 , \\ India
}

\begin{abstract}
Family change theory suggests three ideal-typical family models characterized by different combinations of emotional and material interdependencies in the family. Its major proposition is that in economically developing countries with a collectivistic background a family model of emotional interdependence emerges from a family model of complete interdependence. The current study aims to identify and compare patterns of family-related value orientations related to family change theory across three cultures and two generations. Overall, $N=919$ dyads of mothers and their adolescent children from Germany, Turkey, and India participated in the study. Three clusters were identified representing the family models of independence, interdependence, and emotional interdependence, respectively. Especially the identification of an emotionally interdependent value pattern using a person-oriented approach is an important step in the empirical validation of family change theory. The preference for the three family models differed across as well as within cultures and generations according to theoretical predictions. Dyadic analyses pointed to substantial intergenerational similarities and also to differences in family models, reflecting both cultural continuity as well as change in family-related value orientations.
\end{abstract}

Keywords: family change theory; family models; cross-cultural comparison; intergenerational similarity; person-oriented approach

In cross-cultural research in psychology and sociology as well as in the broader public discourse, questions of family change have been much debated recently (Bengtson, 2001; Georgas, Berry, van de Vijver, Kagitcibasi, \& Poortinga, 2006). Especially in Western cultures there are concerns about a decline of the family, faltering birth rates, and a related loss of social cohesion and solidarity. In many non-Western cultures issues of rising populations and how these are compatible with a sustainable economic and infrastructural development are on the agenda. In cultural psychology, a topic related to the role of the family is the compatibility of autonomy and relatedness in individual selves. Questions discussed concern the nature of autonomy (agency and/or interpersonal distance; Kagitcibasi, 2005), the nature of relatedness (trust vs, assurance; Rothbaum \& Trommsdorff, 2007), the universal human need for both (Kagitcibasi, 2005; Ryan, Deci, \& Grolnick, 1995), and the cultural emphasis laid on one or the other (Keller, 2012). A theoretical approach combining the issue of family development with that of autonomy-relatedness is Kagitcibasi's (2007) family change theory. This contextualist theory of family configurations situates the family and individual selves in ecological and cultural contexts and emphasizes the role of cultural change.

\section{Family change theory: an overview}

Kagitcibasi's (2007) family change theory describes the development of and in families at multiple levels. The first level comprises the overall cultural orientation (e.g; individualism/collectivism) and living conditions (c.g., urban-rural, level of affluence). These cultural and socio-ecological conditions affect the kind of family structure (e.g., nuclear vs. extended families, high or low levels of fertility) that constitutes the second level. Together, these structural variables influence the third level ('family systems') entailing parents' socialization values and practices as well as the developing self and value orientations of their children.

In family change theory an essential distinction is made between material and emotional (or psychological) interdependencies within the family. These two forms of interdependence are differentially emphasized in the three ideal-typical family models identified by Kagitcibasi (2007). First, the family model of independence is typical for Western cultures with an individualist orientation, high affluence, and people living in nuclear families with a low level of fertility. Autonomy is highly valued in this family model and material as well as emotional interdependencies among family members are de-emphasized. Since

\footnotetext{
*Corresponding author. Email: boris.mayer@uni-konstanz.de
} 
there are no economic advantages to having children (social security systems provide old age security independent of parental status) there are only emotional reasons for having children. Childrearing goals emphasize children's independence and uniqueness, and parenting strategies focus mainly on personal autonomy and self-worth, and to a relatively smaller degree on relationships and interpersonal interdependence. Second, the family model of (total) interdependence is prevalent in non-Western, collectivist, and low-affluence cultures where modernization processes have not had a strong impact. This is especially the case in many non-Western rural areas with a low socio-economic development. This family model is characterized by high levels of fertility and by extended families. Children are valued for utilitarian as well as for emotional reasons and have the responsibility to help the family economically and to care for their parents in old age. Strong material as well as emotional interdependencies exist in this family model, and personal autonomy is not highly valued. Third, and as a synthesis of the former two models, Kagitcibasi (2007) proposed the family model of emotional (or psychological) interdependence. In this model, emotional interdependencies stay important while material interdependencies (and traditional hierarchies) weaken as a result of modernization processes in interdependent family cultures. The crucial assumption here is that personal autonomy can rise while emotional closeness and relationship orientation stay intact. Autonomy is no longer perceived as a threat to the family or the group, but as a precondition for functioning in a modern work environment.

Family change theory predicts different patterns of family-related variables, especially with regard to the differential emphasis on material and emotional interdependence. The emphasis on patterns makes the theory amenable to a person-oriented approach that advocates a holistic and interactionist view in which 'the individual is seen as an organized whole, functioning and developing as a totality' (Bergmann \& Magnusson, 1997, p. 291). In contrast, the standard variable-oriented approach analyzes and interprets differences and similarities across and within groups for each of several variables (e.g., value dimensions) separately. The person-oriented approach is necessary when the central theoretical and analytical entity is the specific pattern of operating factors like that of material and emotional interdependencies in family change theory.

Empirical research with regard to family change theory is still not substantial. In a large study of families in 30 cultures, Georgas et al. (2006) analyzed cross-cultural differences and similarities in family values, family roles, and other family-related variables. The comparative results showed that with socio-economic development family values and roles became less traditional and relations with the extended family less close while relations with the nuclear family remained close even in Western affluent cultures.
In the sense of a high (absolute) endorsement (scores above the nid-point in Likert-scales) the results reflect an overall trend towards the family model of emotional interdependence. However, in this study it was difficult to discern actual patterns of differences differentiating the three family models. In a comparison of parenting variables across nine cultures Keller et al. (2006) found an intermediate position of variables representing emotional interdependencics in cultures a priori specified as emotionally interdependent. Similarly, Koutrelakos (2004) demonstrated decreasing material interdependencies but continuing emotional interdependencies with increasing acculturation of Greek Americans. Recent work with urbanizing Inuit parents in Canada (McShane, Hastings, Smylie, Prince, \& Tungasuvvingat Inuit Family Resource Center, 2009) also found both autonomy and relatedness orientations in childrearing - an indicator for the family model of emotional interdependence. Kagitcibasi and Ataca (2005) report comparative analyses from the old and the new VOC-study in Turkey. The results show that material interdependencies were on a steep decline from 30 years ago to the present and the emotional value of children (VOC) gained importance. Furthermore, results from the present VOC-study showed that traditional values and material interdependencies were on the decline from rural to urban groups and from lowto high-affluence cultures as well as from grandmothers to mothers and to adolescents within and across several cultures (Kagitcibasi \& Ataca, 2005; Mishra, Mayer, Trommsdorff, Albert, \& Schwarz, 2005; Trommsdorff, 2009b; Trommsdorff \& Mayer, 2012; Trommsdorff, Mayer, \& Albert, 2004). Overall, these empirical findings offer some support for family change theory. However, none of the studies provides clear evidence by demonstrating patterns of differences of family-related variables that are in accordance with the specific predictions regarding material and emotional interdependencies laid out in family change theory. The current study aims to fill this void by analyzing patterns of family-related values across three cultures and two generations.

The implications of family change theory for modernization theories are far-reaching. According to classical modernization theory, there is no third way combining economic development, democratization, and greater individual freedom with traditional family commitments (Inkeles \& Smith, 1974). Instead, modernization processes will finally lead to a Western independent model that has been idealized as the basis for individual freedom as it has been criticized as a cause for interpersonal alienation and social pathologies in Western societies (e.g., Bellah, Madsen, Sullivan, Swidler, \& Tipton, 1985; Myers, 2001). Yet, if greater individual autonomy should be possible while sustaining strong emotional interdependencies and commitments among family members as in the family model of emotional interdependence, the family can continue to provide shelter and nurturance while at the same time 
freeing the individual to shape his or her life according to individual preferences and talents.

An essential part of family change theory concerns socialization processes and the intergenerational transmission of values. Absolute transmission is characterized by within-family value similarity as well as similarity across cohorts. For relative transmission, the younger generation may overall differ from the older generation, but the withinfamily similarity can be nevertheless high (Vermulst, De Brock, \& Van Zutphen, 1991). In times of cultural change the younger generation is the first to reflect value changes, even if these become effective only when this generation assumes the leading positions in society (Inglehart, 1997). Research on cultural transmission has differentiated between vertical (parent-child), horizontal (peers), and oblique (socialization institutions and parents' peers) transmission (Trommsdorff, 2009a). Furthermore, 'zeitgeist' concerns a value climate resulting from shared context influences (e.g., through mass media) that make the members of a cultural community similar even when intrafamily transmission of values is not functioning (Boehnke, Hadjar, \& Baier, 2007).

\section{Aims of the current study}

The current study is part of the cross-cultural 'Value of Children and Intergenerational Relations (VOC-IR) Project' investigating family values and intergenerational relations in up to now 20 cultures $^{1}$ and across three generations (triads of grandmothers, mothers, and adolescents of both sexes) (Trommsdorff \& Nauck, 2005). Although it would have been preferable to include also (grand-)fathers in the study, for economic reasons only the maternal line could be included. The aim of the current study is to identify and compare composite measures of independent and interdependent family models across three cultures from the VOC-IR Project selected to represent different idealtypical family configurations (Germany, Turkey, and India), and to analyze intergenerational stability and change with regard to these measures. Additionally, intra-cultural comparisons were carried out within the samples from Turkey and India.

Applying a person-oriented approach, the family models are represented by patterns of family-related value orientations. Values refer to the importance of abstract as well as concrete goals in people's lives. The significance of values lies in their motivating function for behavior as well as their function as standards ('oughts' and 'shoulds') for evaluating own and others' behavior (Schwartz, 2006). More specifically, the value orientations included here comprise the dimensions of individualism and collectivism, family values, and two dimensions of the VOC, namely the emotional VOC and the utilitarian-normative VOC. This combination of general and family-specific values well represents the value component of the family models as formulated in Kagitcibasi's theory. While the utilitariannormative VOC with its emphasis on economic reasons for having children represents the domain of material interdependencies, the emotional $\mathrm{VOC}$, the family values as well as the more general collectivistic values represent the domain of emotional interdependencies. Finally, individualistic values are related to an autonomy orientation that comes along with declining material interdependencies in the family. Thus, while some values represent abstract guiding principles in life, others refer to concrete reasons for having children. Both are, however, related to basic human needs of autonomy and relatedness and refer to goals related to fulfilling these needs.

The family model of emotional interdependence is assumed to emerge when collectivistic, interdependent cultures with a low level of affluence develop economically. In our study, Turkey is hypothesized to reflect this family model since it combines a collectivistic background with decade-long modernization processes that resulted in a heightened level of affuence for large parts of the urban population. Germany - as a Western culture with individualistic background and high affluence is hypothesized to reflect the family model of independence. Finally, in India, large parts of the population have not yet experienced changes resulting from modernization processes. Therefore, India is hypothesized to represent the interdependent family model in the current study. Nevertheless, certain within-culture differences are relevant in light of family change theory. Therefore, we differentiated three subsamples in Turkey where, in addition to poor rural areas and urbanized areas with relatively high affluence, there has emerged a low-affluence urban group of people who have recently moved to the city from rural areas but have hardly had the opportunity to move up the social ladder. In India, we differentiated between a very poor rural context, and a relatively well-situated urban context. In Germany, no regional or socio-economic stratification of samples was included since the differences in the level of affluence between urban and rural areas are very low in this culture.

To summarize, the aims of the current study are threefold. The first aim is to identify patterns of cultural and family-related values representing the three family models of independence, interdependence, and emotional interdependence.

- HI: A cluster analysis of the five variables individualism, collectivism, family values, utilitariannormative VOC, and emotional VOC will yield a three cluster solution. The resulting cluster profiles are in accordance with the patterns of material and emotional interdependencies reflecting the three family models described in family change theory.

The second aim is to compare the preference for the resulting family model value profiles across as well as within cultures based on expectations derived from family change theory. 
- H2: In Germany there will be relatively more participants favoring an independent family model (as compared to the two other family models), in Turkey there will be relatively more participants favoring an emotionally interdependent family model, and in India there will be relatively more participants favoring an interdependent family model.

- H3: In all three cultures, relatively more adolescents than mothers will favor a more independent family model. $^{2}$

- H4: Within Turkey and within India, participants from urban and high-SES subsamples will favor a more independent family model ${ }^{2}$ than participants from rural and low-SES subsamples.

The third aim is to analyze parent-child value similarity with respect to family models. The study of the similarity of configurations of values is novel in transmission research. While we assume that overall adolescents will favor a more independent family model than their mothers (cf. H3) we also expect some similarity in motheradolescents dyads:

- H5: There will be significant but only modest crossgenerational agreement with respect to the preference of family models in all three cultures.

\section{Method \\ Participants and procedure}

In Germany, $n=311$ dyads of mothers (age: $M=43.52$ years, $S D=4.90$ years) and their adolescent children (56\% female, age: $M=15.67$ years, $S D=1.07$ years) from three cities (Essen, Konstanz, and Chemnitz) participated in the study. Urban Turkish participants came from Istanbul while rural Turkish participants came from villages in Southwestern Turkey. There were two kinds of Turkish urban participants: high-SES participants belonged to the middle/upper middle class, and low-SES participants had a rural family background and mostly moved to the city only recently. Together, in Turkey $n=308$ dyads of mothers (age: $M=39.80$ years, $S D=5.59$ years) and their adolescent children ( $53 \%$ female, age: $M=14.73$ years, $S D=1.11$ years) participated in the study. Urban Indian participants came from Varanasi, a holy Hindu pilgrimage site that has been called 'miniature India' for the variety of lifestyles and cultural practices of its inhabitants. The Indian rural sample came from villages in the Chandauli district. Overall, in India $n=300$ dyads of mothers (age: $M$ $=40.83$ years, $S D=5.82$ years) and their adolescent children $(51 \%$ female, age: $M=16.01$ years, $S D=1.50$ years $)$ participated in the study. In all three cultures, mothers were interviewed while their adolescent children filled in a questionnaire either at home or in school. To enhance the comparability of procedures, in the interviews mothers were presented with Likert-type scales printed on paper (identical to those in adolescents' questionnaires) where they indicated their responses. For more detailed information on sampling and procedure see Mayer, Albert, Trommsdorff, and Schwarz (2005) (for Germany), Kagitcibasi and Ataca (2005) (for Turkey), and Mishra and colleagues (2005) (for India).

\section{Measures}

The questionnaire (Trommsdorff, Nauck, Schwarz, Chakkarath, \& Schwenk, 2002) included various measures of cultural and family values as well as of intergenerational relationship quality and support. The German, Turkish, and Hindi versions were translated and back translated from the original English version. For the current study, instruments assessing participants' individualism/collectivism, family values, and values of children (VOC) were selected.

Using a procedure suggested by van de Vijver and Leung (1997), we first tested the structural equivalence of the indicators across cultures. Factorial agreement between each culture's principle component factor solution and the pooled solution across all cultures was assessed using Tucker's Phi proportionality coefficients. Phi coefficients of .95 and higher indicate factorial invariance, and coefficients between .90 and .94 indicate acceptable similarity (van de Vijver \& Leung, 1997). We report both Cronbach's alpha and Guttman's $\lambda_{2}$ as measures of scale reliability (Sijtsma, 2009).

Individualism and collectivism were assessed by the respective scales from the COLINDEX (Chan, 1994). Seven items measured individualistic values (e.g., 'Independence (self-reliance, choosing your own goals and interests)'), and 6 items measured collectivistic values (e.g., 'Social order (stability of society)'). Participants rated the importance of these values as a guiding principle in their life from $1=$ 'Not important at all' to $5=$ 'Very important.' Structural equivalence of the two-factor solution was excellent with Tucker's Phis $\geq .95$ for all six (two generations $\times$ three cultures) subsamples for individualism $(M=.97)$ as well as for collectivism $(M=$ 97). Reliabilities were satisfying both for individualism (Cronbach's alpha: $M=.72$, range .68-.75; Guttman's $\lambda_{2}$ : $M=.73$, range $.69-.76$ ) and for collectivism (Cronbach's alpha: $M=.77$, range .68-.84; Guttman's $\lambda_{2}: M=.77$, range $.69-.85$ ).

Family values were measured using a five-item short version based on the instrument developed by Georgas (1991). Items (e.g., 'One should maintain good relationships with one's relatives') were rated from 1 = 'Strongly disagree' to $5=$ 'Strongly agree.' Structural equivalence of the single-factor solution was excellent with Tucker's Phis $=1.0$ for all except one (.99) subsample. Reliabilities were satisfying $(\geq .60)$ with the exception of German 
adolescents (Cronbach's alpha: $M=.71$, range $.58-.85$; Guttman's $\lambda_{2}: M=.72$, range $.59-.85$ ).

The items measuring values of children (VOC) refer to economic, social, and emotional reasons for having children (Arnold et al., 1975; Pohl, 1995). Participants indicated their personal importance of these reasons from $1=$ 'Not important at all' to $5=$ 'Very important.' Prior analyses of the VOC-factor structure (Mayer \& Trommsdorff, 2010) revealed two cross-culturally equivalent dimensions: emotional VOC (seven items, e.g., 'Because of the pleasure you get from watching your children grow') and utilitarian-normative VOC (eight items, e.g., 'Because a child helps around the house'). The structural equivalence of the two-factor solution was excellent in the current study with Tucker's Phis $\geq .95(M=.98)$ for all six subsamples for the emotional VOC and Tucker's Phis $\geq .94$ $(M=.98)$ for the utilitarian-normative VOC. Reliabilities were satisfying both for the emotional VOC (Cronbach's alpha: $M=.81$, range .69-.86; Guttman's $\lambda_{2}: M=.82$, range $.70-.86$ ) and for the utilitarian-normative VOC (Cronbach's alpha: $M=.80$, range $.66-86$; Guttman's $\lambda_{2}$ : $M=.81$, range $.68-.86$ ).

Overall, these preliminary analyses provide strong evidence for structural equivalence of the measures employed. Thus, the respective target language versions of the instruments seem to purport a similar meaning in the different cultural contexts. Also, with few exceptions, satisfactory reliabilities of the measures resulted. We used withinsubject standardized scores to account for differential scale use across cultures (Fischer, 2004; Smith, 2004). Each participant's grand mean across all Likert-type variables in the questionnaire (including a wide range of family-related phenomena beyond the value orientations focused on in the present study) was subtracted from the original scores and the resulting difference was divided by this person's standard deviation.

\section{Results}

\section{Cluster analysis of family-related value orientations}

To identify value profiles that can be related to Kagitcibasi's family change theory, we conducted a cluster analysis across the whole sample using the SPSS two-step cluster module (Bacher, Wenzig, \& Vogler, 2004). This hierarchical cluster procedure includes an informationcriterion-based algorithm to determine the appropriate number of clusters and can identify outliers to eliminate distortions caused by very atypical cases. To avoid effects of the sequence of clustering on the cluster solution we followed Wiedenbeck and Züll's (2001) suggestion to use the cluster centroids resulting from the hierarchical cluster procedure as starting values for a follow-up K-means cluster analysis.

The initial two-step cluster analysis resulted in a threecluster solution, confirming our theoretical assumptions about the existence of three ideal-typical family models (H1). The K-means cluster analysis based on the cluster centroids obtained from the two-step cluster analysis (excluding an outlier cluster of $n=15$ ) resulted in one cluster containing $26.7 \%$ of all cases $(n=488)$, a second cluster containing $36.1 \%(n=659)$, and a third cluster containing $37.2 \%(n=678)$ (see Table 1 for the cluster centroids resulting from the respective analyses).

Cluster 1 was highest in individualism, followed by Cluster 2 and Cluster $3(F(2,1822)=399.25, p<.001$, $\eta^{2}=.31$; all post hoc comparisons $p<.001$; see Figure 1). Cluster 2 was higher in collectivism than Clusters 1 and 3 $\left(F(2,1822)=283.69, p<.001, \eta^{2}=.24\right.$; post hoc comparisons $p<.001$ with the exception of Cluster 1 versus Cluster 3:p=.376). Cluster 2 was also slightly higher on family values than Cluster 3 , and Cluster 1 was lowest on family values $\left(F(2,1822)=257.81, p<.001, \eta^{2}=.22\right.$; all post hoc comparisons $p<.001$ ). The strongest differences resulted for the utilitarian-normative VOC with Cluster 1 showing the lowest scores, closely followed by Cluster 2, and Cluster 3 displaying distinctively higher scores $\left(F(2,1822)=2725.05, p<.001, \eta^{2}=.75\right.$; all post hoc comparisons $p<.001)$. Small but nevertheless significant differences were found for the emotional VOC with Cluster 1 showing the highest values, followed by Cluster 3 and Cluster $2\left(F(2,1822)=47.07, p<.001, \eta^{2}=.05\right.$; all post hoc comparisons $p<.001$ ).

Cluster 3 represented a very traditional outlook on the family while cluster 1 represented a more individualistic and less traditional outlook. Cluster 2 can be characterized by a middle position between Clusters 1 and 3: a relatively high importance of individualism (similar to Cluster 1) is accompanied by high family values (similar to Cluster 3 ) and by low utilitarian-normative values of children (similar

Table 1. Cluster centroids resulting from the two-step cluster analysis and the K-means cluster analysis.

\begin{tabular}{|c|c|c|c|c|c|c|c|c|c|c|}
\hline \multirow[b]{2}{*}{ Cluster no. } & \multicolumn{2}{|c|}{ Individualism } & \multicolumn{2}{|c|}{ Collectivism } & \multicolumn{2}{|c|}{ Family Values } & \multicolumn{2}{|c|}{$\begin{array}{l}\text { Utilitarian-normative } \\
\text { VOC }\end{array}$} & \multicolumn{2}{|c|}{ Emotional VOC } \\
\hline & Two-step & K-means & Two-step & K-means & Two-step & $\mathrm{K}$-means & Two-step & $\mathrm{K}$-means & Two-step & $\mathrm{K}$-means \\
\hline 1 & .77 & .79 & .56 & .55 & .47 & .47 & -1.10 & -1.14 & .70 & .71 \\
\hline 2 & .63 & .61 & 1.00 & .97 & .92 & .88 & -.78 & -.78 & .46 & .47 \\
\hline 3 & .20 & .21 & .56 & .58 & .77 & .78 & .17 & .20 & .57 & .57 \\
\hline
\end{tabular}




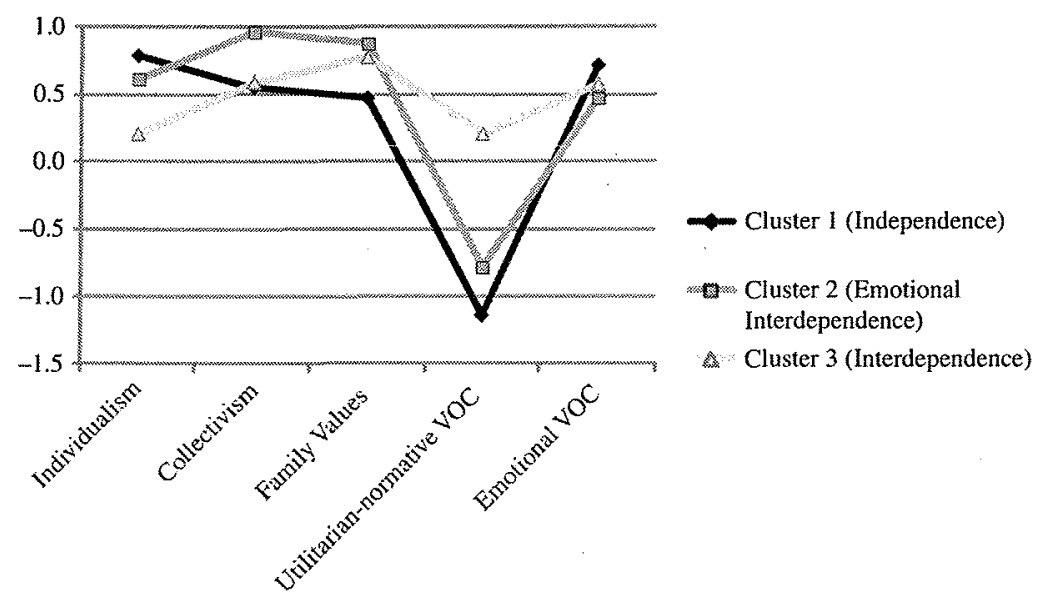

Figure 1. Cluster profiles resulting from the $\mathrm{K}$-means cluster analysis.

Note: Within-subject standardized values.

to Cluster 1). With its emphasis on collectivism and family values (representing emotional interdependencies) and the low importance of utilitarian-normative values of children (representing material interdependencies) Cluster 2 is interpreted to represent the family model of emotional interdependence. In contrast, Cluster 3 represented the family model of interdependence with low individualism and a high importance of both emotional and material interdependencies in the family; and Cluster 1 represented the family model of independence with its emphasis on individualism, relatively low family values and very low utilitarian-normative values of children.

\section{Cross-cultural, cross-regional, and cross-generational comparison of family models}

In the next step, we compared the cluster memberships across cultures, SES/regional groups, and generations. We tested our predictions using multinomial logistic analyses with nominal predictors. To enhance the generalizability of results a model selection approach using the Bayesian Information Criterion (BIC; Schwarz, 1978) was employed. The first model predicted the membership in one of the three family model clusters by culture (Germany, Turkey, and India) and generation (mothers and adolescents). Significant main effects of culture (LR $\chi^{2}(4)=$ $1054.99, p<.001)$ and generation $\left(\mathrm{LR} \chi^{2}(2)=44.04\right.$, $p<.001)$ as well as a significant Culture $\times$ Generation interaction effect $\left(\operatorname{LR} \chi^{2}(4)=22.56, p<.001\right)$ resulted. Since the model including both main effects (but not the interaction effect) yielded the lowest information criterion $(B I C=141.17)$ of all possible models, and especially compared to the full-factorial model $(\mathrm{BIC}=148.65)$, this main effects model was selected as the final model. Thus, the interaction of culture and gencration - although significant
- will not be interpreted since this effect is negligible when considering model parsimony and generalizability of results (in terms of a sample-independent true model) in addition to the statistical significance of the likelihood-ratio test (see Burnham \& Anderson, 2003).

In the final model, all contrast parameters (Waldcoefficients) related to the main effects were significant $(p s<.006)$. The proportions displayed in Table 2 show that our expectations with regard to both cultural and generational differences have been confirmed: The highest prevalence of the independent family model was found in Germany while Turkish participants displayed the highest prevalence of the emotionally interdependent family model, and Indian participants the highest prevalence of the interdependent family model. The generational differences were also in the expected direction: Adolescents reported more independent and less interdependent family models than mothers across all cultures.

Next, we tested within-culture differences in Turkey by differentiating among the three social strata and regional groups (urban high SES, urban low SES, and rural). The main effects of social strata/region $\left(\operatorname{LR} \chi^{2}(4)=197.81\right.$, $p<.001)$ and generation (LR $\left.\chi^{2}(2)=50.57, p<.001\right)$ as well as the Social Strata/Regions $\times$ Generation interaction effect were significant (LR $\chi^{2}(4)=10.65, p=$ .031). Since of all possible models the lowest information criterion resulted for the main effects model (BIC $=$ 113.67; especially in contrast to the full-factorial model: $\mathrm{BIC}=128.71)$ the model including both main effects was selected as the final model. All contrast parameters (Waldcoefficients) in this model were significant (all $p \mathrm{~s}<.001$, except one $p=.016$ ). The distribution of family models within Turkey showed the highest occurrence of the independent family model in the urban high-SES group; the highest occurrence of the emotionally interdependent 
Table 2. Family model cluster memberships across cultures, regions, and generations (percentages).

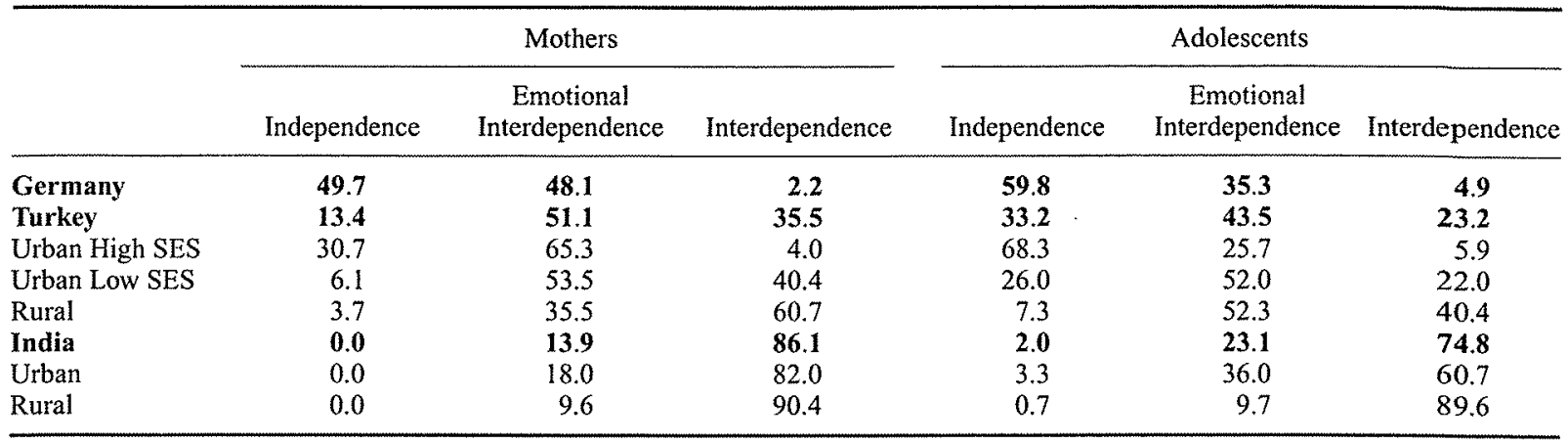

Note: Row percentages per subsample. Percentages may not add up to 100 due to rounding.

family model in the urban low-SES group; and the highest occurrence of the interdependent family model in the rural group (see Table 2). In all three social strata and regional groups generational effects became apparent. A particularly strong difference was found within the urban high-SES group: Here, the proportion of adolescents displaying the independent family model was more than twice as high compared to that of mothers, and vice versa for the emotionally interdependent family model.

Within India we analyzed whether mothers and adolescents as well as rural and urban groups differed regarding their family models. Here, the main effects of region $\left(\mathrm{LR} \chi^{2}(2)=34.92, p<.001\right)$ and generation (LR $\left.\chi^{2}(2)=18.28, p<.001\right)$ were significant while the Region $\times$ Generation interaction effect was non-significant $\left(\operatorname{LR} \chi^{2}(2)=4.04, p=.133\right)$. The main effects model was preferred according to the $\mathrm{BIC}$ criterion $(\mathrm{BIC}=$ 66.84 ; full-factorial model: $\mathrm{BIC}=75.56$ ). In the final main effects model, all but one contrast parameter were significant $(p s<.002)$. The single non-significant Wald coefficient $(p=.088)$ concerned the urban-rural contrast of independence versus interdependence. In India, urban as compared to rural participants were overall more emotionally interdependent and rural as compared to urban participants more interdependent (see Table 2). Hardly any participants preferred an independent family model. While in the urban Indian context mothers were more interdependent and adolescents more emotionally interdependent, in the rural context generational differences were less apparent.

\section{Cross-generational similarity of family models}

We next analyzed in how far mothers and their adolescent children advocate the same or different family models (H5). We applied a measure of exact agreement (Cohen's kappa) as well as a measure of relative agreement (weighted kappa) that treats the three family models as ordinal categories (from independence over emotional interdependence to interdependence). For the latter, if the adolescent prefers a 'neighboring' as compared to an 'opposite' family model relative to the mother's preference, this is defined as relative agreement (using linear weights).

Pan-cultural analysis. In a first step, cross-generational similarity was assessed across the whole sample. A significant Cohen's kappa $=.38, p<.001$, and a significant weighted kappa $=.49, p<.001$, resulted, indicating substantial absolute as well as relative cross-generational agreement. Column-wise percentages are reported since we were especially interested in the distribution of adolescents' family models given a specific mothers' family model (see Table 3 ). The cross-tabulation shows that the cells where mothers and adolescents favor the same family model have the highest column-wise percentages $(68.1 \%$, $44.5 \%$, and $66.9 \%$ for the independent, emotionally interdependent, and the interdependent family model, respectively). The highest percentage of adolescents who favor a family model different from their mothers resulted with regard to the preference of an independent family model when adolescents' mothers preferred an emotionally interdependent family model. Also, if adolescents did not prefer the same family model as their mothers, they tended to prefer a 'neighboring' (and in most cases more independent) family model rather than an opposing family model. The results of the pan-cultural analysis have to be viewed with caution, though, since they combine culture-level and individual-level transmission processes. The cultural preferences for one specific family model (across both generations) apparent in the culture-comparative results reflect cultural stabilities that do not necessarily imply stability within individual families. Nevertheless, these cultural stabilities (in terms of the effect of culture on the family model preferred by both generations) enter into the pancultural agreement coefficients in addition to individuallevel agreement. This is controlled for in the following analyses of within-culture agreement. ${ }^{3}$ 
Table 3. Cross-tabulation of mothers' and adolescents' family model cluster memberships.

\begin{tabular}{|c|c|c|c|c|c|c|c|}
\hline & & \multicolumn{6}{|c|}{ Mothers } \\
\hline & & \multicolumn{2}{|c|}{ Independence } & \multicolumn{2}{|c|}{ Emotional Interdependence } & \multicolumn{2}{|c|}{ Interdependence } \\
\hline & & $n$ & (column\%) & $n$ & $($ column $\%)$ & $n$ & $($ column $\%)$ \\
\hline \multirow{17}{*}{ 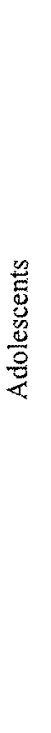 } & $\begin{array}{l}\text { Pan-cultural } \\
\text { Independence }\end{array}$ & 130 & $(68.1)$ & 141 & $(40.8)$ & 20 & $(5.5)$ \\
\hline & Emotional & 53 & $(27.7)$ & 154 & $(44.5)$ & 101 & $(27.6)$ \\
\hline & Interdependence & & & & & & \\
\hline & Interdependence & 8 & $(4.2)$ & 51 & $(14.7)$ & 245 & $(66.9)$ \\
\hline & Germany & & & & & & \\
\hline & Independence & 101 & $(67.3)$ & 79 & $(53.4)$ & 2 & $(28.6)$ \\
\hline & $\begin{array}{l}\text { Emotional } \\
\text { Interdenendence }\end{array}$ & 45 & $(30.0)$ & 60 & $(40.5)$ & 3 & $(42.9)$ \\
\hline & Interdependence & 4 & (2.7) & 9 & $(6.1)$ & 2 & $(28.6)$ \\
\hline & Turkey & & & & & & \\
\hline & Independence & 29 & $(70.7)$ & 60 & $(38.2)$ & 14 & $(12.8)$ \\
\hline & $\begin{array}{l}\text { Emotional } \\
\text { Interdependence }\end{array}$ & 8 & $(19.5)$ & 74 & $(47.1)$ & 52 & $(47.7)$ \\
\hline & Interdependence & 4 & $(9.8)$ & 23 & $(14.6)$ & 43 & $(39.4)$ \\
\hline & India & & & & & & \\
\hline & Independence & & & 2 & $(4.9)$ & 4 & (1.6) \\
\hline & Emotional & & & 20 & $(48.8)$ & 46 & $(18.4)$ \\
\hline & Interdependence & & & & & & \\
\hline & Interdependence & & & 19 & $(46.3)$ & 200 & $(80.0)$ \\
\hline
\end{tabular}

Note: Frequencies and column percentages for mother-adolescent agreement in family model cluster membership. Percentages may not add up to 100 due to rounding.

Culture-specific analysis. Within Germany the generational agreement was low but significant (Cohen's kappa $=.13, p<.01$; weighted kappa $=.15, p<.001)$. The cross-tabulation shows that there were more adolescents who preferred an independent family model when their mothers preferred an emotionally interdependent family model $(53.4 \%)$, than there were adolescents who agreed with their mothers on the emotionally interdependent family model ( $40.5 \%$, see Table 3$)$.

In Turkey, intergenerational agreement was somewhat higher with Cohen's kappa $=.19, p<.001$, and weighted kappa $=.27, p<.001$. A high proportion of Turkish adolescents favored an independent family model when their mothers favored an emotionally interdependent family model $(38.2 \%)$. For mothers with an interdependent family model, a higher proportion (47.7\%) of adolescent 'changed' to the emotionally interdependent family model as compared to adolescents favoring an interdependent family model like their mothers $(39.4 \%$, see Table 3$)$.

In India, a Cohen's kappa $=.24, p<.001$, and a weighted kappa $=.24, p<.001$, resulted. Since a great majority of Indian mothers and adolescents preferred the interdependent family model, there were also a high absolute number of mothers and adolescents who agreed on the preference of this family model (see Table 3 ).

\section{Discussion}

Three important results can be summarized. First, three patterns of cultural and family-related value orientations were identified that were theoretically related to the idealtypical family models formulated in Kagitcibasi's (2007) family change theory. Second, the preference for these patterns differed across the three cultures, across social strata and regions within Turkey and India, and across generations in accordance with predictions based on family change theory. Third, there was significant intergenerational value similarity with regard to the identified family models, both across and within cultures. Thus, none of our hypotheses had to be rejected.

With regard to the identification of the family-related value patterns the pattern representing the family model of emotional interdependence is theoretically most interesting. On the one hand, it is similar to the value profile representing the family model of interdependence in terms of a high importance of family values. This reflects the strong relationship orientation among family members in the emotionally interdependent model. On the other hand, it is similar to the value profile representing the family model of independence with respect to (relatively) high individualism and a low utilitarian-normative VOC. This reflects declining material interdependencies in the family as well 
as a rising autonomy orientation. Since the emotionally interdependent family model is characterized by a diverging pattern of emotional and material interdependencies, its identification in a person-oriented approach is an important step in the empirical validation of family change theory.

A differentiation of material and emotional interdependencies in terms of utilitarian versus emotional values of children was the starting point of Kagitcibasi's family change theory. As has been shown, the utilitarian-normative VOC accounts for the difference. This value seems to decline steeply in the process of societal development, thus reflecting declining material interdependencies between generations. In contrast, the emotional VOC is hardly relevant for the distinction of family models. It is high in all three family models, and even highest in the independent model. Therefore, its role as reffecting an overall high relationship orientation in the family has to be reconsidered. Rather, the emotional VOC seems to have a universal importance (see also Mayer \& Trommsdorff, 2010).

The cross-cultural differences in the preference of the three family models show that the majority of German participants prefer the independent family model while the majority of Turkish and Indian participants prefer the emotionally interdependent and the interdependent family model, respectively. The additional cross-regional comparisons within Turkey and India confirm the cross-cultural results: In Turkey, independent orientations seem to be on the rise in urban contexts, especially in the adolescent generation. In India, some urban adolescents seem to adhere to an emotionally interdependent view in contrast to the overall interdependent orientation in this culture. ${ }^{4}$ Finally, in all three cultures as well as in the regional comparisons (with the exception of rural India) mothers were overall more (emotionally) interdependent than adolescents. These differences in family models across and within cultures show clearly that both the level of economic development and the general cultural background are shaping family models - a major proposition of family change theory.

We found significant intergenerational similarity of family models across and within cultures. The withinculture generational similarity is significant in all three cultures, but not very high. Unlike correlational similarity indicators for single variables that can be high even in case of strong group differences, the agreement indices used in the current study are sensitive to absolute changes. Overall, the results suggest a relative rather than absolute transmission of family models (cf. Vermulst et al., 1991).

The overall importance of these results lies in the fact that we can observe both cultural stability of family models as well as some stability within individual families. Nevertheless, there are strong indicators for cultural change: First, many adolescents prefer a more independent family model than their mothers; and second, participants from more economically developed areas (within cultures that exhibit strong regional differences) prefer a more independent family model than those from economically less developed areas. Together, these results provide evidence for a stability of family models from a transmission perspective as well as evidence for cultural change from the perspective of family change theory.

Although we have treated the three family models as distinct configurations we have also considered them as ordered categories because of the process component inherent in family change theory: with economic development and modernization, interdependent cultures are assumed to change to emotionally interdependent cultures. Nevertheless, the question is still unresolved whether the family model of emotional interdependence might be a transitional phenomenon that will finally lead to the independent family model - as suggested, for example, by the results of the urban Turkish adolescents in this study. These results have to be viewed with caution, however, since the current study is cross-sectional and can only extrapolate results from comparisons of cultures (or regions/social strata) considered typical for different types of and stages in societal development. Also, the 'independent' value pattern identified here is not as independent as it seems: though family values are lower than in the other models they are not low in terms of absolute scores (cf. Georgas et al., 2006). In a similar vein, Kagitcibasi (2007) suggests that the emphasis on the independent self in Western cultures may be more a cultural ideal than reality. In addition, we might observe a convergence from the family model of interdependence but also from independence to the more balanced family model of emotional interdependence.

The cross-sectional design is a serious limitation of the current study. It is always dangerous to speculate on processes of cultural change from cross-cultural comparisons (Thornton, 2005). Furthermore, representativeness of the samples cannot be claimed, overall but especially for the multiethnic Indian context. Nevertheless, we have included typical samples from several sites per culture and differentiated between rural and urban contexts where necessary. An additional limitation is that the family-related value patterns identified in the current study are based on only three cultures. Future studies have to test whether similar configurations can be obtained with a larger number of cultures. A specific strength of the present study is the inclusion of several aspects of family-related value orientations, including the VOC, in a person-oriented approach that fits the configurational framework of family change theory. Family values are important ideational components of family models (Jayakody, Thornton, \& Axinn, 2008) but they do not represent the full range of variables necessary for a complete validation of family change theory. Thus, future studies have to focus on further components of family models beyond family values. With regard to transmission 
processes, the current study's focus is on intergenerational similarity. This focus should be broadened in future studies to include the analysis of transmission processes.

In sum, the current study constitutes an important contribution to research related to Kagitcibasi's (2007) family change theory. The identification of three distinct family models through patterns of abstract and concrete family-related value orientations as well as the evidence of cross-cultural and within-cultural variation (and stability) with respect to these family models substantiate central propositions of family change theory. Though a number of questions remain, the results show that autonomy and relatedness can coexist in the family model of emotional interdependence. This coexistence can be empirically differentiated from more extreme (either very independent or very interdependent) family models emphasized in different cultural and socio-economic contexts.

\section{Acknowledgments}

This study is part of the of the cross-cultural and interdisciplinary research project 'Value of Children and Intergenerational Relations.' Principal investigators: Gisela Trommsdorff, University of Konstanz, Germany, and Bernhard Nauck, Chemnitz University of Technology, Germany. In Germany and Turkey the study was funded by the German Research Foundation (TR 169/9-1, -2, -3 and NA 164/9-1, -3, -4). In India, the study was co-funded by the University of Konstanz and the German Research Foundation. The authors would like to thank the following members of the VOC-team: Bilge Ataca (Turkey); Bernhard Nauck, Beate Schwarz, Daniela Klaus, Jana Suckow, and Isabelle Albert (Germany).

\section{Notes}

1. We use the term culture when referring to countries throughout the text. Though differences within cultures are important, especially in diverse and multiethnic countries like India, the consideration of relatively large cultural units defined by political boundaries has proven useful for the study of broad cultural differences.

2. This can include the emotionally interdependent family model (characterized by material independence) in cultures where overall the (totally) interdependent family model is being preferred.

3. Cohen's kappa compares the agreement resulting by chance (based on the marginal distributions) with the de facto empirical agreement (of two raters or as in this case: of two generations). A positive kappa thus denotes that the empirical agreement is higher than the agreement expected by chance. When different groups that have very different marginal distributions (e.g., in Germany a majority of participants - both mothers and adolescents - prefer the independent family model while in India a majority prefer the interdependent family model) are combined as in the pan-cultural analysis, the true (individual-level) chance agreement is underestimated because it is based on the marginal distributions of the combined sample rather than on the marginal distributions of the single samples, thus resulting in an inflated Cohen's kappa.
4. Varanasi represents a relatively traditional urban cultural setting in India. It is likely that we would have found more participants preferring an emotionally interdependent family model had the study been carried out in big cities such as Delhi or Mumbai.

\section{References}

Arnold, F., Bulatao, R.A., Buripakdi, C., Chung, B.J., Fawcett, J.T., Iritani, T., et al. (1975). The value of children. A crossnational study (Vol. 1). Honolulu, HI: East-West Population Institute.

Bacher, J., Wenzig, K., \& Vogler, M. (2004). SPSS TwoStep Cluster - a first evaluation. Nürnberg, Germany: FriedrichAlexander-Universität, Lehrstuhl für Soziologie, Arbeits- und Diskussionspapier, February 2, 2004.

Bellah, R.N., Madsen, R., Sullivan, W.M., Swidler, A., \& Tipton, S.M. (1985). Habits of the heart. Individualism and commitment in American life. London: Hutchinson.

Bengtson, V.L. (2001). Beyond the nuclear family: The increasing importance of multigenerational bonds. Journal of Marriage and the Family, 63, 1-16. doi: 10.1111/j.17413737.2001.00001.x

Bergmann, L.R., \& Magnusson, D. (1997). A person-oriented approach in research on developmental psychopathology. Development and Psychopathology, 9, 291-319. doi: 10.1017/S095457949700206X

Boehnke, K., Hadjar, A., \& Baier, D. (2007). Parentchild value similarity: The role of zeitgeist. Journal of Marriage and Family, 69, 778-792. doi: 10.1111/j.17413737.2007.00405.x

Burnham, K.P., \& Anderson, D.R. (2003). Model selection and multimodel inference: A practical information-theoretic approach (2nd ed.). New York, NY: Springer.

Chan, D.K.-S. (1994). COLINDEX: A refinement of three collectivism measures. In U. Kim, H.C. Triandis, C. Kagitcibasi, S.-C. Choi, \& G. Yoon (Eds.), Individualism and collectivism: Theory, method, and applications (pp. 200-210). Thousand Oaks, CA: Sage.

Fischer, R. (2004). Standardization to account for cross-cultural response bias: A classification of score adjustment procedures and review of research in JCCP. Journal of Cross-Cultural Psychology, 35, 263-282. doi: 10.1177/0022022104264122

Georgas, J. (1991). Intrafamily acculturation of values in Greece. Journal of Cross-Cultural Psychology, 22, 445-457. doi: $10.1177 / 0022022191224001$

Georgas, J., Berry, J.W., van de Vijver, F.J.R., Kagitcibasi, C, \& Poortinga, Y.H. (Eds.). (2006). Families across cultures. Cambridge: Cambridge University Press.

Inglehart, R. (1997). Modernization and postmodernization: Cultural, economic, and political change in 43 societies. Princeton, NJ: Princeton University Press.

Inkeles, A., \& Smith, D.H. (1974). Becoming modern: Individual change in six developing countries. London: Heinemann.

Jayakody, R., Thornton, A., \& Axinn, W.G. (2008). Perspectives on international family change. In R. Jayakody, A. Thornton, \& W.G. Axinn (Eds.), International family change. Ideational perspectives (pp. 1-18). New York, NY: Erlbaum.

Kagitcibasi, C. (2005). Autonomy and relatedness in cultural context. Journal of Cross-Cultural Psychology, 36, 403-422. doi: 10.1177/0022022105275959

Kagitcibasi, C. (2007). Family, self, and human development across cultures: Theory and applications ( 2 nd ed.). Hillsdale, NJ: Erlbaum. 
Kagitcibasi, C., \& Ataca, B. (2005). Value of children and family change: A three-decade portrait from Turkey. Applied Psychology: An International Review, 54, 317-337. doi: 10.1111/j.1464-0597.2005.00213.x

Keller, H. (2012). Autonomy and relatedness revisited Cultural manifestations of universal human needs. Child Development Perspectives, 6, 12-18. doi: $10.1111 / \mathrm{j} .1750$ 8606.2011.00208.x

Keller, H., Lamm, B., Abels, M., Yovsi, R., Borke, J., Jensen, H., ... Chaudhary, N. (2006). Cultural models, socialization goals, and parenting ethnotheories. Journal of Cross-Cultural Psychology, 37, 155-172. doi: 10.1177/0022022105284494

Koutrelakos, J. (2004). Acculturation of Greek Americans: Change and continuity in cognitive schemas guiding intimate relationships. International Journal of Psychology, 39 95-105. doi: 10.1080/00207590344000213

Mayer, B., Albert, I., Trommsdorff, G., \& Schwarz, B. (2005). Value of children in Germany: Dimensions, comparison of generations, and relevance for parenting. In G. Trommsdorff \& B. Nauck (Eds.), The value of children in cross-cultural perspective: Case studies from eight societies (pp. 43-65). Lengerich, Germany: Pabst Science.

Mayer, B., \& Trommsdorff, G. (2010). Adolescents' value of children and their intentions to have children: A crosscultural and multilevel analysis. Journal of Cross-Cultural Psychology, 41, 671-689. doi: 10.1177/0022022110372195

McShane, K.E., Hastings, P.D., Smylie, J.K., Prince, C., \& Tungasuvvingat Inuit Family Resource Center. (2009). Examining evidence for autonomy and relatedness in urban Inuit parenting. Culture \& Psychology, 15, 411-431. doi: 10.1177/1354067X09344880.

Mishra, R.C., Mayer, B., Trommsdorff, G., Albert, I., \& Schwarz, B. (2005). The value of children in urban and rural India: Cultural background and empirical results. In $\mathrm{G}$. Trommsdorff \& B. Nauck (Eds.), The value of children in cross-cultural perspective: Case studies from eight societies (pp. 143-170). Lengerich, Germany: Pabst Science.

Myers, D.G. (2001). The American paradox: Spiritual hunger in an age of plenty. New Haven, CT: Yale University Press.

Pohl, K. (1995). Design und Struktur des deutschen FFS [Design and structure of the German FFS]. Materialien zur Bevölkerungswissenschaft: Familienbildung und Kinderwunsch in Deutschland, Heft $82 a$. Wiesbaden, Germany: Bundesinstitut für Bevölkerungsforschung.

Rothbaum, F, \& Trommsdorff, G. (2007). Do roots and wings complement or oppose one another? The socialization of relatedness and autonomy in cultural context. In J.E Grusec \& P. Hastings (Eds.), The handbook of socialization (pp. 461-489). New York, NY: The Guilford Press.

Ryan, R.M., Deci, E.L., \& Grolnick, W.S. (1995). Autonomy, relatedness, and the self: Their relation to development and psychopathology. In D. Cicchetti \& D.J. Cohen (Eds.), Developmental psychopathology, Vol.1: Theory and methods (pp. 618-655). New York, NY: Wiley.
Schwartz, S.H. (2006). A theory of cultural value orientations: Explication and applications. Comparative Sociology, 5, 136-182. doi: 10.1163/156913306778667357

Schwarz, G. (1978). Estimating the dimension of a model. Annals in Statistics, 6, 461-464. doi: 10.1214/aos/1176344136

Sijtsma, K. (2009). On the use, the misuse, and the very limited usefulness of Cronbach's Alpha. Psychometrika, 74, 107-120. doi: 10.1007/s]1336-008-9101-0

Smith, P.B. (2004). Acquiescent response bias as an aspect of cultural communication style. Journal of Cross-Cultural Psychology, 35, 29-49. doi: 10.1177/0022022103260380

Thornton, A. (2005). Reading history sideways. The fallacy and enduring impact of the developmental paradigm on family life. Chicago, IL: University of Chicago Press.

Trommsdorff, G. (2009a). Intergenerational relations and cultural transmission. In U. Schönpflug (Ed.), Cultural transmission: Psychological, developmental, social, and methodological aspects (pp. 126-160), Cambridge: Cambridge University Press.

Trommsdorff, G. (2009b). A social change and a human development perspective on the value of children. In S. Bekman \& A. Aksu-Koc (Eds.), Perspectives on human development, family and culture (pp. 86-107). Cambridge: Cambridge University Press.

Trommsdorff, G., \& Mayer, B. (2012). A cross-cultural study of intergenerational relations. In $\mathrm{H}$. Bertram \& $\mathrm{N}$. Ehlert (Eds.), Family, ties, and care. Family transformation in a plural modernity (pp. 315-342). Opladen, Germany: Barbara Budrich.

Trommsdorff, G., Mayer, B., \& Albert, I. (2004). Dimensions of culture in intra-cultural comparisons: Individualism/collectivism and family-related values in three generations. In H. Vinken, J. Soeters, \& P. Ester (Eds.), Comparing cultures: Dimensions of culture in a comparative perspective (pp. 157-179). Leiden, The Netherlands: Brill Academic.

Trommsdorff, G., \& Nauck, B. (Eds.). (2005). The value of children in cross-cultural perspective: Case studies from eight societies. Lengerich, Germany: Pabst Science.

Trommsdorff, G., Nauck, B., Schwarz, B., Chakkarath, P., \& Schwenk, O. (2002). VOC-IR questionnaire for adolescents. Unpublished Questionnaire. University of Konstanz and University of Chemnitz, Germany.

van de Vijver, F.J.R., \& Leung, K. (1997). Methods and data analysis for cross ${ }^{-C u l t u r a l}$ research. Thousand Oaks, CA: Sage.

Vermulst, A.A., De Brock, A.J.L.L., \& Van Zutphen, R.A.H. (1991). Transmission of parenting across generations. In P.K. Smith (Ed.), The psychology of grandparenthood (pp. 100-122). London: Routledge.

Wiedenbeck, M., \& Züll, C. (2001). Klassifikation mit ClusterAnalyse: Grundlegende Techniken hierarchischer und K-means Verfahren [Classification asing chuster analysis: Basic techniques of hierarchical and K-means procedures]. ZUMA How-to-Reihe, 10, 1-18. 